Article

\title{
Synthesis and Characterization of Copper-Based Composites Reinforced by CuZrAlNiTi Amorphous Particles with Enhanced Mechanical Properties
}

\author{
Kinga Tomolya ${ }^{1}$, Anna Sycheva ${ }^{1}$, Maria Sveda ${ }^{1}$, Peter Arki ${ }^{2}$, Tamas Miko ${ }^{1}$, Andras Roosz ${ }^{1}$ \\ and Dora Janovszky ${ }^{1, *}$ \\ 1 MTA-ME Materials Science Research Group, Miskolc-Egyetemvaros H-3515, Hungary; \\ femkinga@uni-miskolc.hu (K.T.); femanna@uni-miskolc.hu (A.S.); femmaria@uni-miskolc.hu (M.S.); \\ femmiko@uni-miskolc.hu (T.M.); femroosz@uni-miskolc.hu (A.R.) \\ 2 Institute of Physical Metallurgy, Metalforming and Nanotechnology, University of Miskolc, \\ Miskolc-Egyetemvaros H-3515, Hungary; arkipeter91@gmail.com \\ * Correspondence: fekjd@uni-miskolc.hu
}

Academic Editor: Manoj Gupta

Received: 9 February 2017; Accepted: 8 March 2017; Published: 11 March 2017

\begin{abstract}
Novel amorphous/crystalline composites were developed combining the ductile copper matrix with hard $\mathrm{CuZr}$-based amorphous powder. The amorphous powders of two compositions, $\mathrm{Cu}_{39.2} \mathrm{Zr}_{36} \mathrm{Al}_{14.8} \mathrm{Ni}_{10} \mathrm{Ti}_{10}$ and $\mathrm{Cu}_{39.2} \mathrm{Zr}_{35.2} \mathrm{Al}_{5.6} \mathrm{Ni}_{10} \mathrm{Ti}_{10}$, produced by ball milling were used for reinforcement of the composites. Different mixing techniques, magnetic mixing, ultrasonic mixing and high-energy ball milling, were applied in order to create a homogenous mixture of the powders. The composites were produced by hot pressing under a purified argon atmosphere. Their microstructure, homogeneity and mechanical properties were investigated. It was observed that before hot pressing, minimal porosity had been obtained for the composite blended for $15 \mathrm{~min}$ by the ball-mill with a ball-to-powder ratio of 80:1. Its copper content was $50 \mathrm{wt} \%$, which is the minimum to produce a compact composite. Reinforcing the copper by amorphous powders, the maximal compressive strength was enhanced to $490 \mathrm{MPa}$ and $470 \mathrm{MPa}$, respectively, for the abovementioned composites. The yield strength of the copper due to reinforcement increased drastically from $150 \mathrm{MPa}$ to $400 \mathrm{MPa}$ and $420 \mathrm{MPa}$.
\end{abstract}

Keywords: amorphous/crystalline composite; ball-milling; powder metallurgy; hot pressing; microstructure; mechanical properties

\section{Introduction}

Particle-reinforced metal matrix composites $\left(\mathrm{MMC}_{\mathrm{p}}\right)$ have been studied over the past decades. Combining the large ductility of the matrix with the high hardness (strength, stiffness) of the reinforcement, a new composite with enhanced mechanical properties can be created. Recently, CuZr-based metallic glasses have attracted great attention due to their high strength and high thermal stability against crystallization with lower costs than $\mathrm{Zr}$-based metallic glasses. $\mathrm{Cu}, \mathrm{Zr}$ and $\mathrm{Al}$ have advantageous properties such as good toughness indicated by their high Charpy impact value, good corrosion resistance, and high glass-forming ability (GFA) [1]. Amorphous particles can be produced by mechanical milling or mechanical alloying [2,3]. In the last years, amorphous particulate reinforced lightweight metal $(\mathrm{Al}[4,5], \mathrm{Mg}$ [6-8]) composites were investigated owing to their high specific strength and low density. The metallic nature of the reinforcing phase plays an important role in achieving good bonding between the matrix and the glassy reinforcement in contrast to the usual conventional ceramic reinforcing phases, where detrimental interfacial reactions often occur. Ceramics 
display low wettability by the metal matrix, which generates particle agglomeration and porosity as well. Due to the amorphous reinforcements, a significant enhancement of mechanical properties (e.g., strength) was reported [4-10]. The yield strength of pure Mg increased from $70 \mathrm{MPa}$ to $85 \mathrm{MPa}$ owing to a $3 \% V_{f} \mathrm{NiNb}$ amorphous reinforcement [7]. The yield strength of Al-2024 increased from $270 \mathrm{MPa}$ to $403 \mathrm{MPa}$ due to $15 \mathrm{wt} \%$ Fe-based metallic glass reinforcement [10]. The ultimate tensile strength of the $2 \mathrm{vol} \% \mathrm{TiCNp} / \mathrm{Al}-11 \mathrm{Si}$ composite is $222 \mathrm{MPa}$ [11]. High-strength and high-conductivity materials are highly needed in industry for contact wires, electric resistance welding electrodes, etc. Notable effort can be observed in the development of materials with significant copper content because the mechanical properties of copper need to be improved without significantly reducing its thermal and electrical conductivity. Generally, the mechanical properties of copper can be improved by solid solution strengthening (traditionally by alloying) or introducing a second reinforcing phase [12-15]. A variety of copper-based materials, e.g., $\mathrm{Cu}-\mathrm{Al}_{2} \mathrm{O}_{3}, \mathrm{Cu}-\mathrm{TiB}_{2}, \mathrm{Cu}-\mathrm{SiO}_{2}, \mathrm{Cu}-\mathrm{TiC}$, have been developed by different techniques. However, ceramics decrease the electrical and thermal conductivity of the alloys and composites.

It is expected of a composite that a strong matrix/reinforcement interface forms without any chemical reaction, dissolution or debonding because of its pivotal function in the strengthening. A suggested solution is the use of a reinforcement material similar in chemistry to the matrix [16]. These enhanced properties of the composites are influenced by the uniform distribution of the amorphous particles and the appropriate reinforcement/matrix interface.

Considering the common preparation methods, introducing an amorphous phase into the crystalline matrix can be carried out by powder metallurgy (PM) route, hot pressing, infiltration casting, vacuum hot pressing combined with hot extrusion, and microwave hot pressing [5-10].

It is well known that the creation of homogenous particle-reinforced composites is based on the blending of the phases because the agglomeration of the particles causes voids and porosity. There are several opportunities to blend the particles, resulting in a considerably homogeneous distribution of one material within the other. In most cases, blending can be carried out wet and dry using a high-energy ball-mill or (two- or three-dimensional) shaker mixers [17-20].

The aim of this study is to create an amorphous particle-reinforced crystalline copper matrix composite with homogeneous particle distribution and high strength. CuZr-based, ball-milled amorphous powder was used as the reinforcement. The paper is intended primarily to examine the effect of the mixing techniques on the homogeneity of the phases by analyzing the macro- and microstructure. The second aim is to reveal the minimal amount of additional matrix material required for reducing the porosity in the microstructure. Furthermore, the composites are characterized by compressive tests and hardness measurements.

\section{Experimental Procedures}

Master alloy ingots with the compositions $\mathrm{Cu}_{39.2} \mathrm{Zr}_{36} \mathrm{Al}_{4.8} \mathrm{Ni}_{10} \mathrm{Ti}_{10}$ and $\mathrm{Cu}_{39.2} \mathrm{Zr}_{35.2} \mathrm{Al}_{5.6} \mathrm{Ni}_{10} \mathrm{Ti}_{10}$, respectively were prepared by arc melting of pure metal mixtures under purified argon atmosphere. Amorphous powders were obtained in a Pulverisette 5 high-energy ball-mill in argon atmosphere [21]. Crystalline copper powder of 99.9 wt \% purity was added with a mass percentage of 30, 40 and 50 to the amorphous powders. Different mixing techniques were applied to obtain homogenous mixture of powders. Table 1 summarizes the composite samples under investigation and their mixing techniques. Wet mixing in alcohol (hereinafter referred to as "magnetic mixing") was carried out using a Heidolph MR Hei-Standard magnetic stirrer (Heidolph, Schwabach, Germany) at room temperature with $1000 \mathrm{rpm}$ for $10 \mathrm{~min}$. An UP200S ultrasonic processor (Hielscher, Teltow, Germany) was also used as homogenizer. Ultrasonic homogenizing is a mechanical process to mix small particles so that they become uniformly distributed. The source of ultrasound was immersed in the dry powder and emitted ultrasonic waves for $15 \mathrm{~min}$. High-energy ball-mill with different parameters was used for mixing of the samples in the dry state as well. The ball-to-powders ratio was 20:1 and 80:1. The mixing process lasted 5, 10 and $15 \mathrm{~min}$. 
Table 1. Techniques and parameters.

\begin{tabular}{ccccc}
\hline Samples & $\begin{array}{c}\text { Composition of } \\
\text { Amorphous Powder (at \%) }\end{array}$ & $\begin{array}{c}\text { Mixing } \\
\text { Techniques }\end{array}$ & $\begin{array}{c}\text { Copper } \\
\text { Powder (wt \%) }\end{array}$ & $\begin{array}{c}\text { Parameters } \\
\text { of Mixing }\end{array}$ \\
\hline MM1 & & Magnetic & 30 & $1000 \mathrm{rpm}$ \\
MM2 & & Magnetic & 40 & $1000 \mathrm{rpm}$ \\
MM3 & & Magnetic & 50 & $1000 \mathrm{rpm}$ \\
UM1 & & Ultrasonic & 30 & $10 \mathrm{kHz}$ \\
UM2 & $\mathrm{Cu}_{39.2} \mathrm{Zr}_{36} \mathrm{Al}_{4.8} \mathrm{Ni}_{10} \mathrm{Ti}_{10}$ & Ultrasonic & 40 & $10 \mathrm{kHz}$ \\
BM1 & Ball-milling & 30 & $20: 1,5 \mathrm{~min}$ \\
BM2 & & Ball-milling & 40 & $20: 1,5 \mathrm{~min}$ \\
BM3 & & Ball-milling & 50 & $20: 1,5 \mathrm{~min}$ \\
BM4 & & Ball-milling & 50 & $80: 1,5 \mathrm{~min}$ \\
BM5 & & Ball-milling & 50 & $80: 1,10 \mathrm{~min}$ \\
BM6 & & Ball-milling & 30 & $80: 1,15 \mathrm{~min}$ \\
BM7 & & Ball-milling & 40 & $80: 1,15 \mathrm{~min}$ \\
BM8 & $\mathrm{Cu}_{39.2} \mathrm{Zr}_{35.2} \mathrm{Al}_{5.6} \mathrm{Ni}_{10} \mathrm{Ti}_{10}$ & Ball-milling & 50 & $80: 1,15 \mathrm{~min}$ \\
BM9 & & & & $80: 15 \mathrm{~min}$ \\
\hline
\end{tabular}

The mixed powders were hot-pressed at $390^{\circ} \mathrm{C}$ under $1 \mathrm{GPa}$ pressure for $4 \mathrm{~h}$ in high-purity argon atmosphere in order to obtain amorphous/crystalline composites. This optimal temperature is high enough to form metallic bonding between the particles and low enough not to allow crystallization of amorphous powders. Samples with a diameter of $7 \mathrm{~mm}$ and a height of $7 \mathrm{~mm}$ were produced.

After standard metallographic preparation, the microstructure, homogeneity and porosity of each composite were investigated by a Quantimet Image Analyser using Leica Software (LeicaQWinProV2.3, Leica, Wetzlar, Germany). The microstructure was analyzed by a Hitachi S4800 Field Emission Scanning Electron Microscope (SEM, Hitachi, Tokio, Japan) equipped with a Bruker AXS Energy-dispersive X-ray Spectrometer (EDS) system.

Hardness measurements were performed by a Wolpert UH 930 equipment (Illinois Tool Works Test and Measurement, Shanghai, China) applying a load of $30 \mathrm{~kg}$ for $15 \mathrm{~s}$ for all composites. The microhardness of initial powders was measured using a load of $50 \mathrm{~g}$ for $15 \mathrm{~s}$. The particle size of the amorphous powders was measured by a Horiba LA-950 V2 particle size analyser (Horiba, Kyoto, Japan). Compression tests were carried out by an Instron 5982 electromechanical universal material testing equipment (Instron, Grove, PA, USA) with a strain rate of $1 \times 10^{-2} \mathrm{~s}^{-1}$ and $1 \times 10^{-4} \mathrm{~s}^{-1}$ at room temperature. Three samples of each composition were measured.

\section{Results and Discussion}

\subsection{Analysis of the Initial Powders}

Figure 1 shows the morphology of the initial copper powder, which has a spherical structure with an average particle size of $\sim 50 \mu \mathrm{m}$. It can be observed that the powder contains a mixture of round-shaped particles of sizes up to $50-60 \mu \mathrm{m}$ and sizes of a few micrometers, as well. The particles coagulate, which prohibits the homogenous mixing of the copper and the amorphous powders. The average Vickers microhardness of copper powder is $56 \mathrm{HV}_{0.05}$. 

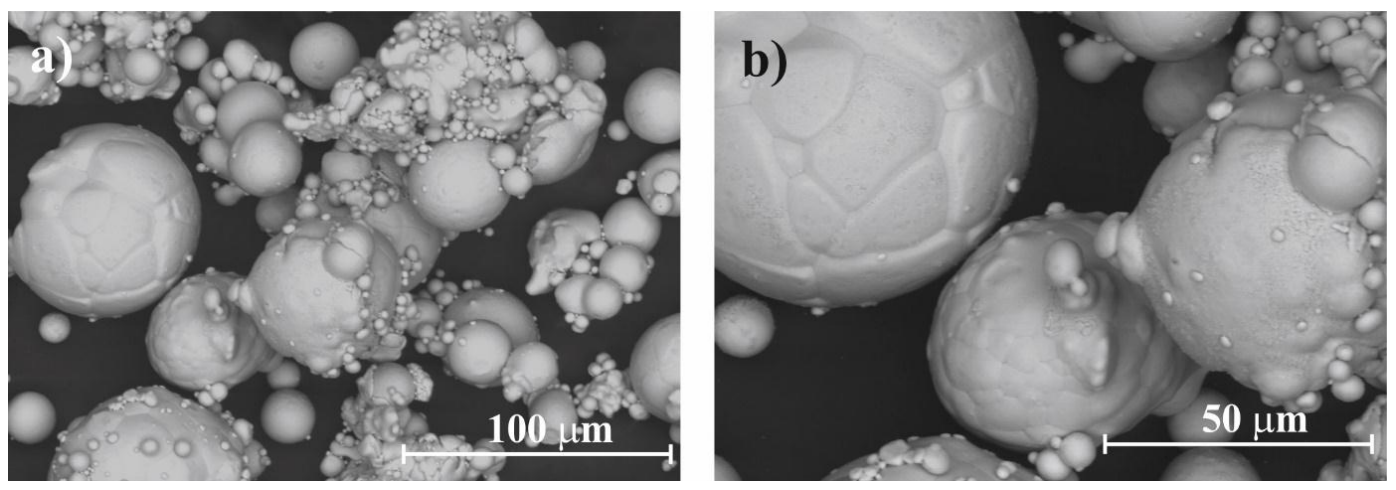

Figure 1. (a,b) SEM micrographs of the copper powder at different magnifications.

Figure 2 introduces the morphology of the amorphous powders obtained by ball milling. Two compositions with different particle sizes and hardness were selected. They have an average particle size of $29 \mu \mathrm{m}$ with a Vickers hardness of $593 \pm 44 \mathrm{HV}_{0.05}$ for $\mathrm{Cu}_{39.2} \mathrm{Zr}_{36} \mathrm{Al}_{4.8} \mathrm{Ni}_{10} \mathrm{Ti}_{10}$ and $74 \mu \mathrm{m}$ with $690 \pm 28 \mathrm{HV}_{0.05}$ for $\mathrm{Cu}_{39.2} \mathrm{Zr}_{35.2} \mathrm{Al}_{5.6} \mathrm{Ni}_{10} \mathrm{Ti}_{10}$, respectively. The effect of milling can be observed as cavities, pores and microcracks in the particles.

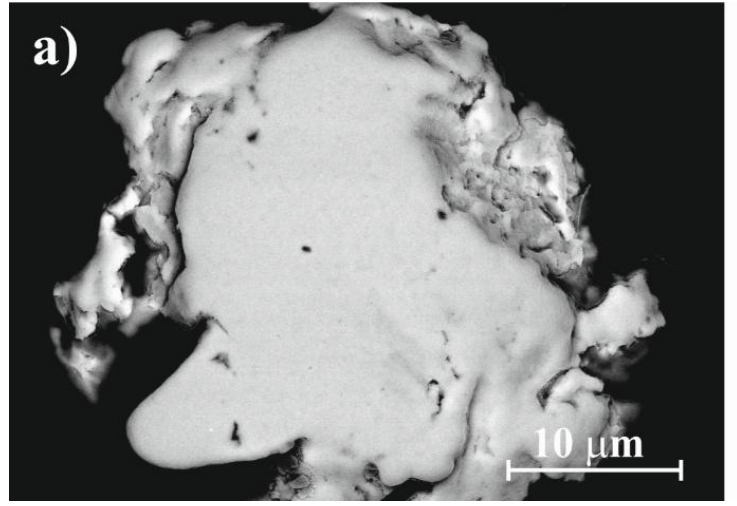

Figure 2. SEM micrographs of the amorphous (b) $\mathrm{Cu}_{39.2} \mathrm{Zr}_{35.2} \mathrm{Al}_{5.6} \mathrm{Ni}_{10} \mathrm{Ti}_{10}$.

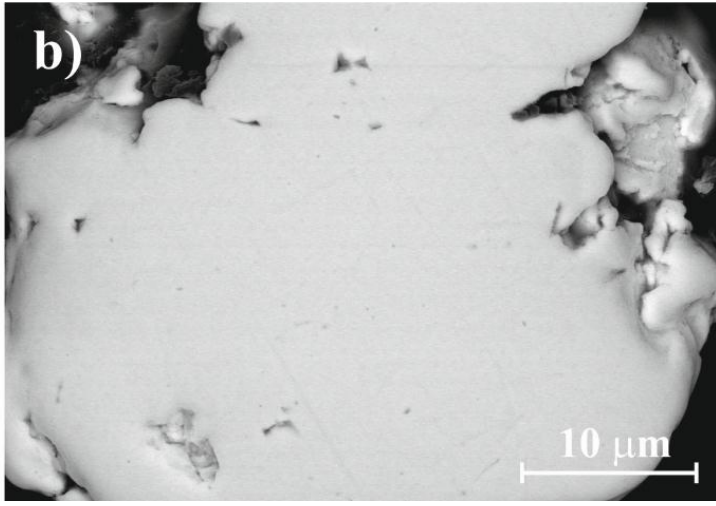

(a) $\mathrm{Cu}_{39.2} \mathrm{Zr}_{36} \mathrm{Al}_{4.8} \mathrm{Ni}_{10} \mathrm{Ti}_{10}$;

\subsection{Effect of the Amorphous-to-Crystalline Ratio on the Microstructure}

Figure 3 presents the SEM images of the compacts with copper amounts of 30 to $50 \mathrm{wt} \%$. The copper was sintered at $390^{\circ} \mathrm{C}$ with no porosity owing to the high pressure of $1 \mathrm{GPa}$. As can be seen, the increasing content of the copper powder in the composites shows the same trend regardless of the mixing method. There are pores between the amorphous particles (AM) in the cases of 30 and $40 \mathrm{wt} \%$ copper in the composites. These amounts of copper are still not enough to form an interconnected network of copper particles with homogenous dispersion of the amorphous particles. As shown in Figure $3 \mathrm{c}, \mathrm{f}, 50 \mathrm{wt} \%$ of copper seems to be a sufficient amount to cover and separate the amorphous particles. The network obtained can improve the sinterability, which may lead to a high density of the composite [22]. Furthermore, consolidation of the samples can be improved by modifying the mixing methods. 

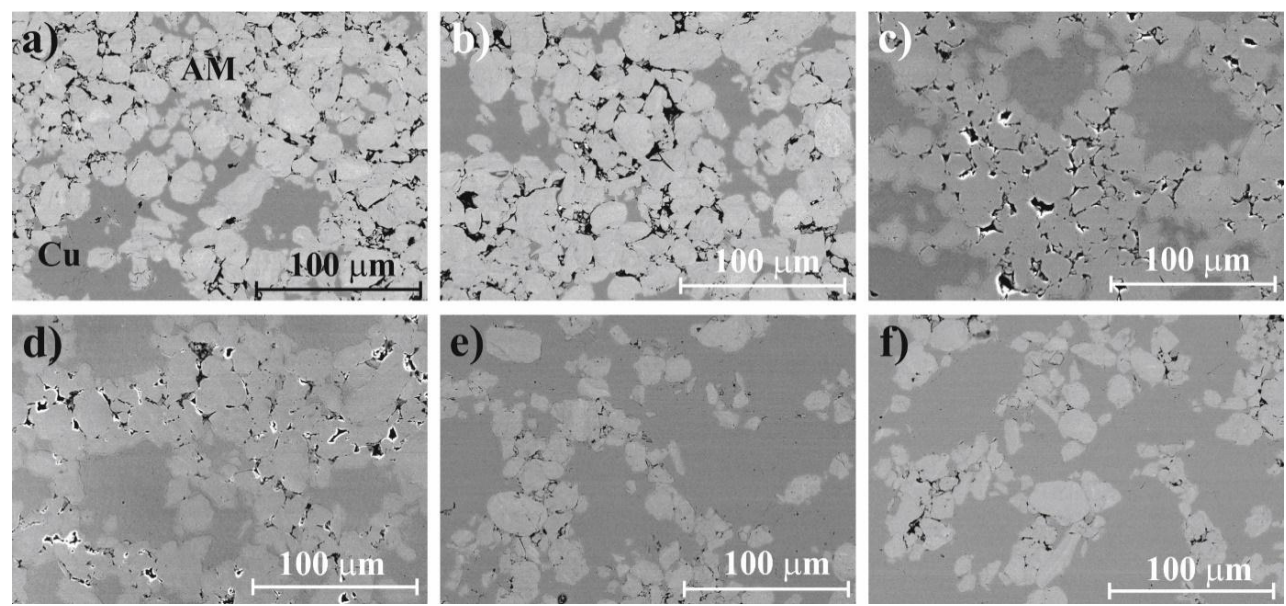

Figure 3. Effect of the copper amount on the microstructure (a) MM1; (b) MM2; (c) MM3; (d) BM1; (e) BM2; (f) BM3.

\subsection{Effect of Mixing on the Homogeneity}

The hot-compacted composites exhibit different homogeneity, which is influenced by the mixing technique. Based on Section 3.2, the $50 \mathrm{wt} \%$ copper composite was selected for further investigations. Figure 4 introduces the effect of various mixing techniques. The difference between the compacts is perceptible to the naked eye in the macrographs. The white particles are the copper grains and the grey ones are the amorphous grains. Magnetic mixing (MM) produces a visibly homogeneous dispersion of the particles (Figure 4a). Ultrasonic mixed (UM) compacts have weak homogeneity, and the white particles of copper show the mixing lines (Figure $4 \mathrm{~b}$ ), which is especially visible in both compacts mixed by the ultrasonic technique. Mixing by ball milling (BM) gives the appropriate result of a homogenous dispersion of both phases, which can be enhanced by adjusting the parameters. The BM with a short duration (maximum $15 \mathrm{~min}$ ) and a ball-to-powder ratio of 20:1 resulted in better homogeneity in comparison to UM (Figure 4c), which can be improved by increasing the ball-to-powder ratio up to 80:1 (Figure 4d).
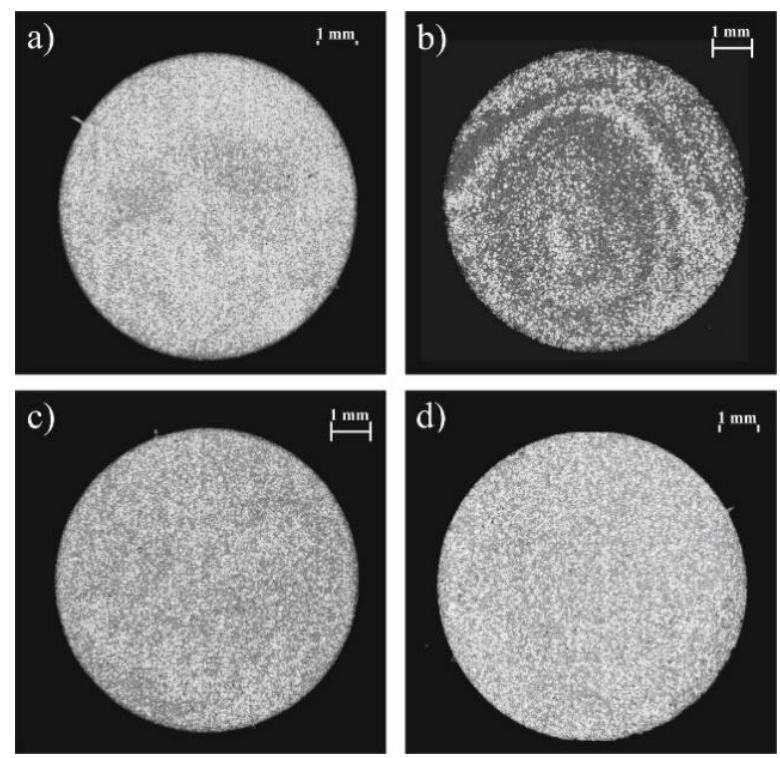

Figure 4. Macrographs of hot compacts mixed by (a) magnetic mixing (MM2); (b) ultrasonic mixing (UM2); (c) ball milling with a ball-to-powder ratio of 20:1 (BM2); (d) ball milling with a ball-to-powder ratio of 80:1 (BM4). 
The radial distribution function (RDF) was applied for the numerical characterization of the amorphous particle arrangement, which was successfully applied to $\mathrm{Al} / \mathrm{SiC}$ composites by Z. Gácsi et al. [23]. This function presents the relative density of particles $(\mathrm{H}(\mathrm{r}))$ in the analyzed area. The measurement and calculation of the geometrical density of amorphous powders was performed on the micrographs of the composites. Concentric circular discs were drawn in the pictures. The number of amorphous powders was calculated inside the measuring ring by the following equation:

$$
H(r)=\frac{\frac{N_{i}}{A_{i}}}{\frac{N}{A}}
$$

where $N_{i}$ is the number of particles inside the " $i$ " ring; $A_{i}$ is the area of the " $I$ " $\operatorname{ring}\left(\right.$ pixel $^{2}$ ); $N$ is the total number of particles in the visual field; $A$ is the total visual field area (pixel ${ }^{2}$ ) [23]. Four typical arrays (hexagonal, square, random and clustered) can be distinguished by this theory in order to describe the amorphous particle arrangement in the copper matrix. The inhomogeneity of the particle distribution can be indicated by the number and height of $\mathrm{H}(\mathrm{r})$ peaks (Figure 5). Magnetic mixing is not recommended for these powders (Figure 5a). By increasing the ball-to-powder ratio in ball milling, the homogeneity was slightly improved. Moreover, observing the effect of the milling time on the homogeneity (Figure 5b), it can be concluded that this effect is not as strong as the ball-to-powder ratio. In the case of the alloys with other compositions (BM9), random arrangement of the particles can be achieved by mixing in a ball-mill with the following parameters: 15 min milling time and 80:1 ball-to-powder ratio, because the relative density values are around 1 (Figure 5c).
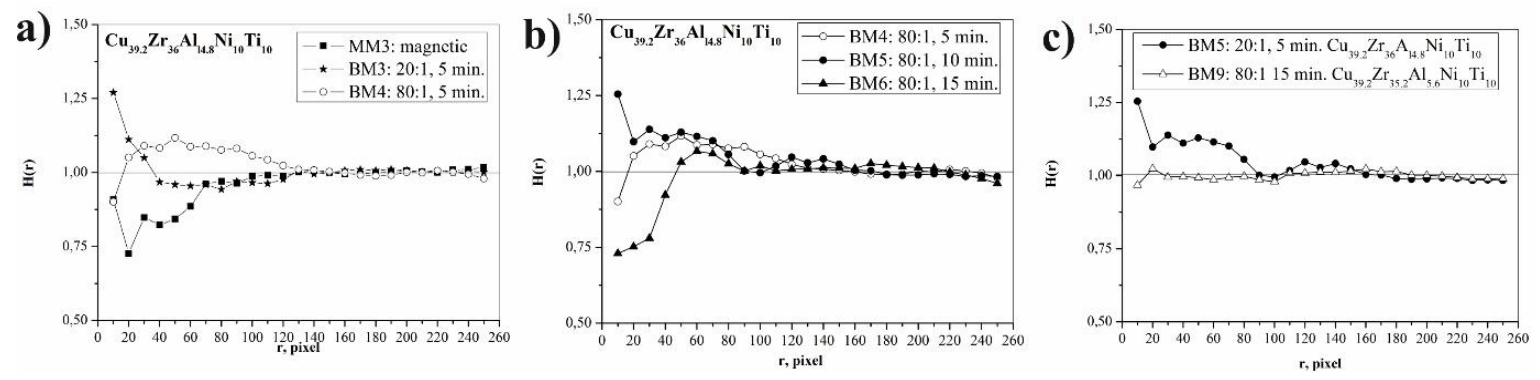

Figure 5. RDF curves of compacted samples with different mixing techniques.

\subsection{Microstructure after Consolidation}

High-resolution backscattered images of composites ball-milled with a ball-to-powder ratio of 80:1 are illustrated in Figure $6 a-d$. Figure $6 a-c$ demonstrate the effect of the milling time on the microstructure of composites containing the amorphous powder of the $\mathrm{Cu}_{39.2} \mathrm{Zr}_{36} \mathrm{Al}_{4.8} \mathrm{Ni}_{10} \mathrm{Ti}_{10}$ composition. These pictures show the phase contrast between the darker grey copper matrix and the brighter amorphous reinforcing phase. Already after 5 min of milling, the contact surfaces between the two different phases are continuous and gapless. However, local powder agglomerations of amorphous powder result in porosity in the microstructure. Increasing the milling time, the agglomerations of the amorphous powder decreased (Figure 6e-g). These powders need 15 min of mixing before hot pressing to become homogeneous and compact (Figure 6c,d). 

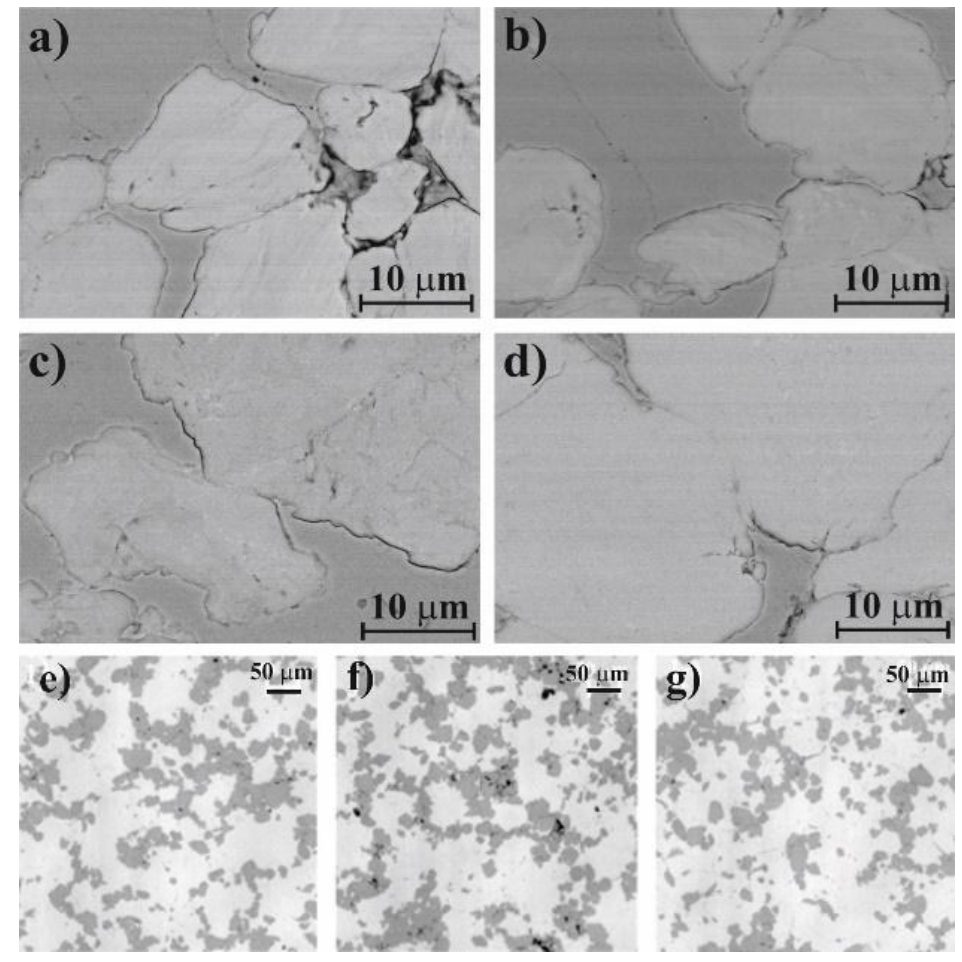

Figure 6. Microstructure of composites ball-milled with a ball-to-powder ratio of 80:1, (a-c) $\mathrm{Cu}_{39.2} \mathrm{Zr}_{36} \mathrm{Al}_{4.8} \mathrm{Ni}_{10} \mathrm{Ti}_{10}$ (a) $5 \mathrm{~min}$ (BM4); (b) $10 \mathrm{~min}$ (BM5); (c) $15 \mathrm{~min}$ (BM6); (d) $15 \mathrm{~min}$ $\mathrm{Cu}_{39.2} \mathrm{Zr}_{35.2} \mathrm{Al}_{5.6} \mathrm{Ni}_{10} \mathrm{Ti}_{10}$ (BM9); (e) 5 min (BM6); (f) $10 \mathrm{~min}$ (BM6); (g) $15 \mathrm{~min}$ (BM6).

Figure 7 shows the amorphous halo and peaks of the crystalline copper for both composites. It confirms that the reinforcing particles have retained their amorphous structure after hot pressing.

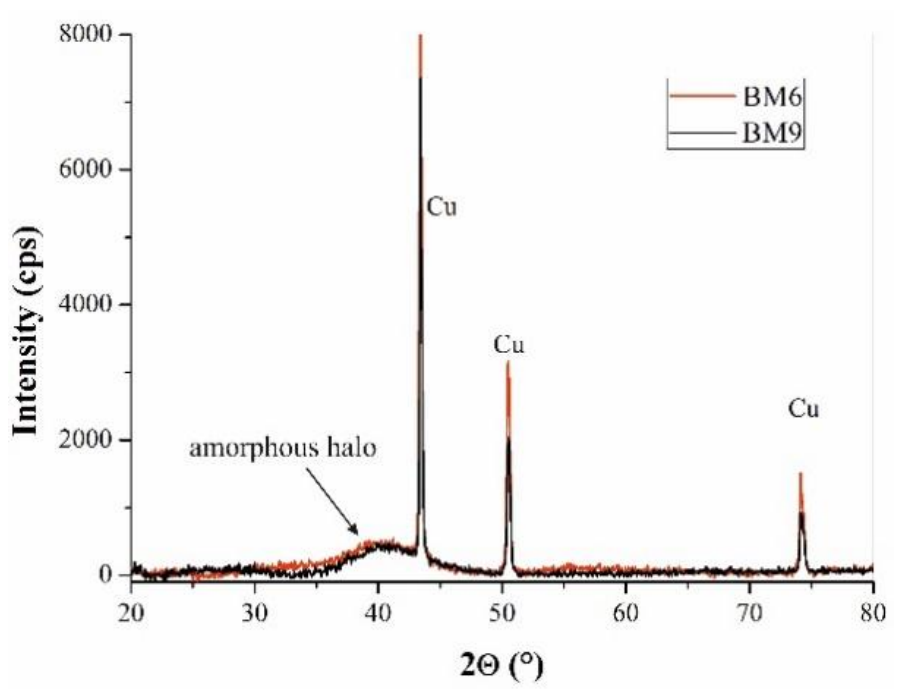

Figure 7. XRD patterns of composites after hot pressing.

\subsection{Mechanical Properties}

Composites display enhanced mechanical properties owing to the properties and volume fraction of the reinforcing phase. In order to observe the effect of the amorphous phase on the mechanical properties, compression tests were performed on the composites prepared with the optimal parameters 
(blending by ball-mill with a ball-to-powder ratio of 80:1 for $15 \mathrm{~min}$, using $50 \mathrm{wt}$. \% of copper in the mixture, hot pressing at $390^{\circ} \mathrm{C}$ with $1 \mathrm{GPa}$ pressure for $4 \mathrm{~h}$ in a high-purity argon atmosphere).

Figure $8 \mathrm{a}, \mathrm{b}$ show the stress-strain curves of the compressed materials, while Figure $8 \mathrm{c}$ introduces the macrographs of the samples after the tests. The compressive strength-strain curve of copper (the initial copper powder used as the matrix) displays a typical plastic curve with a hardening effect. The compressive strength of the pressed pure copper reaches $350 \mathrm{MPa}$ at $0.5 \%$ of strain. The maximal compressive strength is $490 \mathrm{MPa}$ (BM6) and $470 \mathrm{MPa}$ (BM9). The compressive stress-strain curves of the composites can be divided into four segments. In the first interval (between points 0 and 1 in Figure $8 \mathrm{a}, \mathrm{b})$, the material deforms elastically, the entire specimen deforms homogeneously, and no plastic flow occurs. When the stress reaches point 1 , the soft $\mathrm{Cu}$ matrix begins deforming plastically, and part of the load is transferred to the amorphous particles. The stress grows at the interfaces between the matrix and particles, resulting in micro-cracks as reported in [24]. At point 2, the micro-cracks originate from the $\mathrm{Cu}$ matrix and propagate inside the sample. Further increasing the load, cracks were observed to propagate through the amorphous particles. The $\mathrm{Cu}$ matrix fills the gaps between the cracked particles. When the stress approaches point 3, the behavior of stress-strain curve has a similarity to the pure $\mathrm{Cu}$ sample.
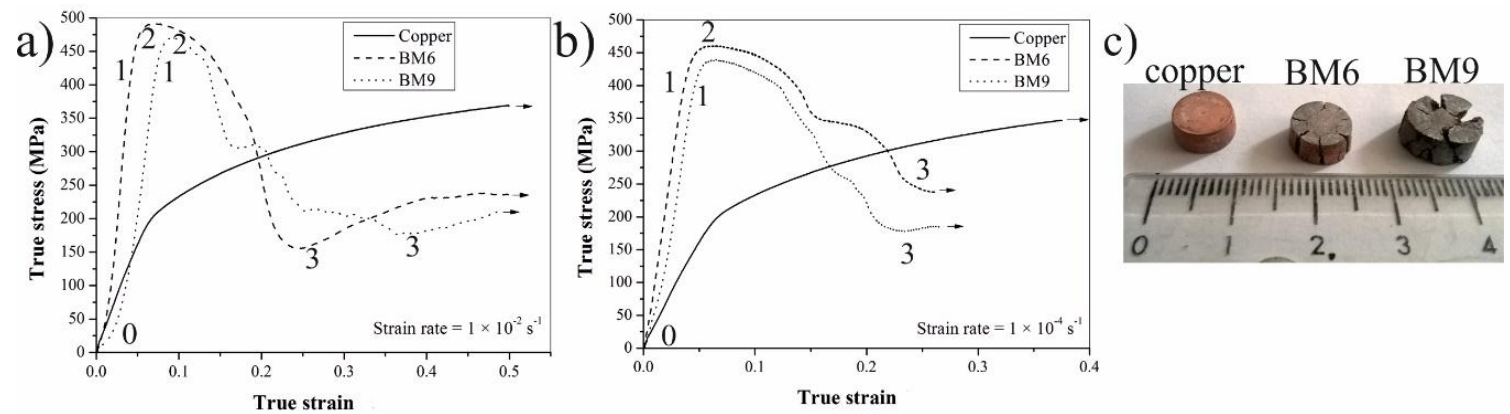

Figure 8. Compressive stress-strain curves of the composites: (a) strain rate of $10^{-2} \mathrm{~s}^{-1}$; (b) strain rate of $10^{-4} \mathrm{~s}^{-1}$; (c) macrographs of the compressed samples.

Decreasing the strain rate from $1 \times 10^{-2} \mathrm{~s}^{-1}$ to $1 \times 10^{-4} \mathrm{~s}^{-1}$, the maximal compressive strength reduced slightly to $460 \mathrm{MPa}$ in the case of BM6 and $440 \mathrm{MPa}$ in the case of BM9. All in all, by reinforcing the copper with amorphous powders, the maximal compressive strength can be significantly improved. It is implied that the appropriate combination of these materials significantly improves the strength of the composite.

It can be observed (Figure 8c) that the copper does not reflect any external damage, and the only upset of the sample took place due to the compressive forming. An obvious difference can be seen between the copper and the composites. Cracks were found in the lateral surface of the composites, which are parallel to the compression direction. Based on visual observation, the visible cracks on the surface appeared after exceeding the maximum stress and moved into the central part of the samples with the increasing strain. It is assumed that the plastic deformation of the copper matrix was deflected by the amorphous particles. Under further compression and beyond the maximal compression stress, the stress decreased slowly below the elastic limit, especially in the case of the strain rate from $1 \times 10^{-2} \mathrm{~s}^{-1}$. Then the stress increased slightly and afterwards remained constant with the increasing strain, indicating a steady-state stage in the case of all composite samples. Comparing the effect of the two amorphous reinforcing particles, it can be established that the softer amorphous particles improved the mechanical properties of the $\mathrm{Cu}$ matrix more effectively.

The yield strength of the copper was enhanced drastically owing to the reinforcement (Figure 9) from $150 \mathrm{MPa}$ to $400 \mathrm{MPa}$ (BM6) and $420 \mathrm{MPa}$ (BM9), thus more than twice. It means that the elasticity of the composites was higher than that of the copper. Direct comparison of the present mechanical data with those from other $\mathrm{Cu}$-based composites reinforced by oxides and carbides is not possible 
because of the different techniques and reinforcing phases used; however, it is worth comparing some literary data. A Cu-based nanostructured composite with 5 vol \% $\mathrm{Al}_{2} \mathrm{O}_{3}$ obtained by high-energy mechanical milling has a yield strength value of $486 \mathrm{MPa}$ [8]; with $5 \mathrm{vol} \% \mathrm{TiC}$, it reaches $661 \mathrm{MPa}$ [11]. The composition Cu-2.4Ti-0.6C (mass \%) prepared by two-step ball milling has a yield strength equal to $421-572 \mathrm{MPa}$, as reported in [10]. As concerns the effect of the strain rate, it can be established that the yield strength barely increases with higher strain rate. The results of the hardness correlate with the yield strength values. The Vickers hardness of copper can be improved by the reinforcement from $100 \mathrm{HB} 1 / 30$ to 112 (BM6) and significantly in the case of BM9 to 135 HB1/30 (Figure 9).

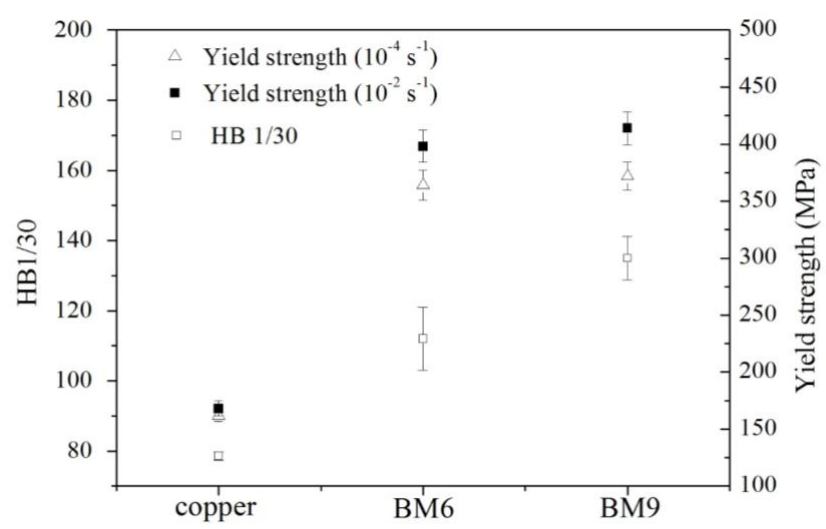

Figure 9. Brinell hardness and yield strength of the composites and copper.

Figure 10 presents the fracture surface of the composites after the compression test. The amorphous powder and the matrix can hardly be distinguished from each other in the backscattered images owing to their similar gray scale. However, they can be recognized due to the different fracture surface. It can be clearly observed that the amorphous powder has a smooth flat surface after breaking, while copper has a typical ductile fracture (Figure 10e). Three typical destruction steps were discovered based on Figure 10b,d: first of all, the interfacial bond between the two phases started to weaken and cracks appeared, causing a complete break as reported in [25]. Secondly, cracks were deflected by the amorphous powders, and thirdly, cracks propagated through the amorphous particles.

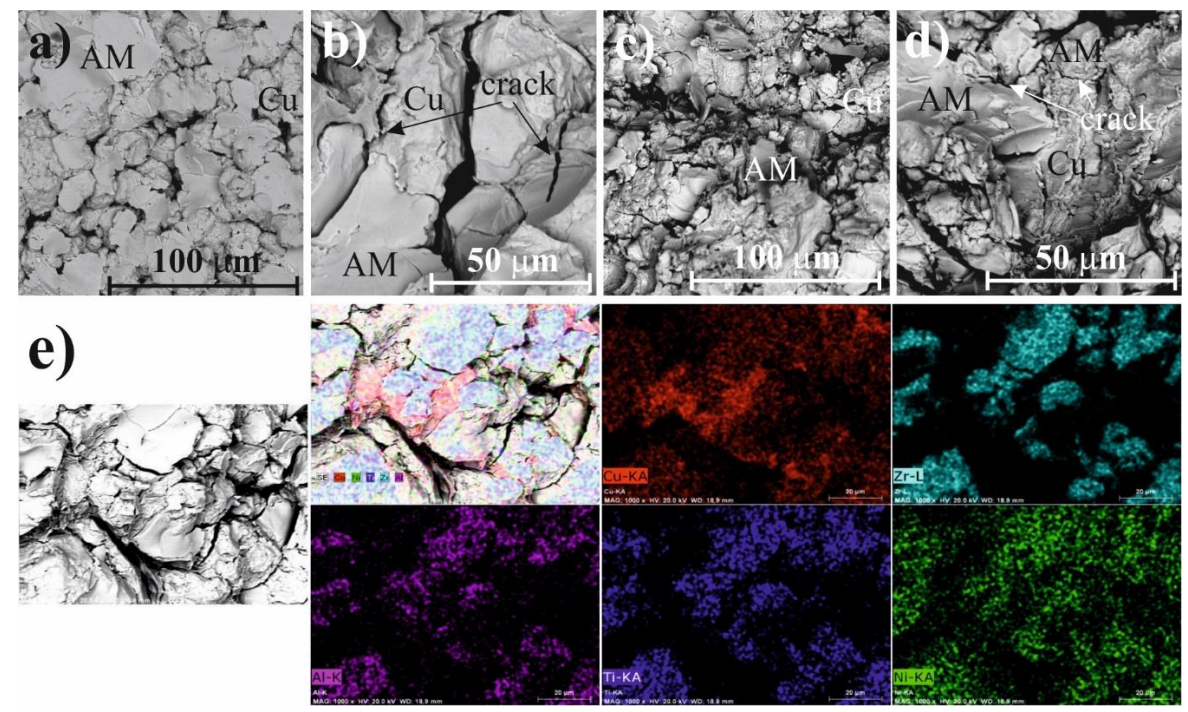

Figure 10. Fracture surface of the composites (a,b) BM6; (c,d) BM9 (AM: amorphous powder, Cu: copper powder); (e) BM6 EDS elemental map of the same area. 
Figure 11 introduces the cross-section of the samples after the compression test. The amorphous powders broke due to the stress, although the copper matrix deformed plastically. Copper was pressed (injected) by the stress into the gaps of broken amorphous particles.
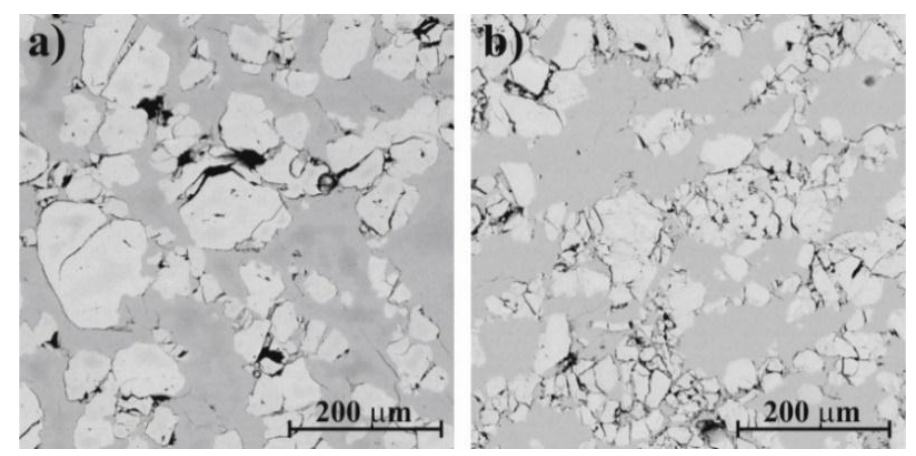

Figure 11. Cross-section of the samples after compression test (a) BM6; (b) BM9.

\section{Conclusions}

In summary, new amorphous/crystalline composites were developed by combining ductile copper with hard CuZr-based amorphous powder. Minimal porosity (less than $2 v / v \%$ ) was obtained for the composite blended by the ball-mill with a ball-to-powder ratio of 80:1 for 15 min before hot pressing. The minimum copper content to produce a compact composite is $50 \mathrm{wt}$. \%. Furthermore, this method seems to be the perfect route to blend the powders in view of the random arrangement of amorphous particles in the copper matrix. A clear and continuous interface can be observed between the phases in the composites. The amorphous reinforcement provides a significant increase in the compressive strength, yield strength and hardness. Under compression, the copper matrix holds the stress by plastic deformation, while the amorphous phases act as obstacle for the cracks, improving the mechanical values.

Acknowledgments: The research work was carried out as part of the OTKA K 112623 project.

Author Contributions: Kinga Tomolya conceived and designed the study. Kinga Tomolya, Dora Janovszky, Peter Arki performed the experiments and analysis. Anna Scheva and Maria Sveda provided the SEM analyses. Tamas Miko provided the compressive tests analysis. Kinga Tomolya, Anna Sycheva and Dora Janovszky wrote the manuscript. Roosz helped perform the analysis with constructive discussions. All authors read and approved the manuscript.

Conflicts of Interest: The authors declare no conflict of interest.

\section{References}

1. Marques, P.W.B.; Chaves, J.M.; Silva, P.S.; Florêncio, O.; Moreno-Gobbi, A.; Aliaga, L.C.R.; Botta, W.J. Mechanical spectroscopy study on the $\mathrm{Cu}_{54} \mathrm{Zr}_{40} \mathrm{Al}_{6}$ amorphous matrix alloy at low temperature. J. Alloys Compd. 2015, 621, 319-323. [CrossRef]

2. Suryanarayana, C. Mechanical alloying and milling. Prog. Mater. Sci. 2001, 46,1-184. [CrossRef]

3. Bachaga, T.; Daly, R.; Escoda, L.; Suñol, J.J.; Khitouni, M. Amorphization of $\mathrm{Al}_{50}\left(\mathrm{Fe}_{2} \mathrm{~B}\right)_{30} \mathrm{Nb}_{20}$ mixture by mechanical alloying. J. Metall. Mater. Trans. A 2013, 44, 4718-4724. [CrossRef]

4. Prashanth, K.G.; Kumar, S.; Scudino, S.; Murty, B.S.; Eckert, J. Fabrication and Response of $\mathrm{Al}_{70} \mathrm{Y}_{16} \mathrm{Ni}_{10} \mathrm{Co}_{4}$ Glass Reinforced Metal Matrix Composites. Mater. Manuf. Process. 2011, 26, 1242-1247. [CrossRef]

5. Wang, Z.; Tan, J.; Sun, B.A.; Scudino, S.; Prashanth, K.G.; Zhang, W.W.; Li, Y.Y.; Eckert, J. Fabrication and mechanical properties of Al-based metal matrix composites reinforced with $\mathrm{Mg}_{65} \mathrm{Cu}_{20} \mathrm{Zn}_{5} \mathrm{Y}_{10}$ metallic glass particles. Mater. Sci. Eng. A 2014, 600, 53-58. [CrossRef]

6. Dastgerdi, J.N.; Marquis, G.; Anbarlooie, B.; Sankaranarayanan, S.; Gupta, M. Microstructure-sensitive investigation on the plastic deformation and damage initiation of amorphous particles reinforced composites. Compos. Struct. 2016, 142, 130-139. [CrossRef] 
7. Jayalakshmi, S.; Sahu, S.; Sankaranarayanan, S.; Gupta, S.; Gupta, M. Development of novel Mg- $\mathrm{Ni}_{60} \mathrm{Nb}_{40}$ amorphous particle reinforced compo sites with enhanced hardness and compressive response. Mater. Des. 2014, 53, 849-855.

8. Sankaranarayanan, S.; Shankar, V.H.; Jayalakshmi, S.; Bau, N.Q.; Gupta, M. Development of high performance magnesium composites using $\mathrm{Ni}_{50} \mathrm{Ti}_{50}$ metallic glass reinforcement and microwave sintering approach. J. Alloys Compd. 2015, 627, 192-199. [CrossRef]

9. Dudina, D.V.; Georgarakis, K.; Aljerf, M.; Li, Y.; Braccini, M.; Yavari, A.R.; Inoue, A. Cu-based metallic glass particle additions to significantly improve overall compressive properties of an $\mathrm{Al}$ alloy. Compos. Part A 2010, 41, 1551-1557. [CrossRef]

10. Zheng, R.; Yang, H.; Liu, T.; Ameyama, K.; Ma, C. Microstructure and mechanical properties of aluminum alloy matrix composites reinforced with Fe-based metallic glass particles. Mater. Des. 2014, 53, 512-518. [CrossRef]

11. Wang, K.; Jiang, H.Y.; Wang, Y.X.; Wang, Q.D.; Ye, B.; Ding, W.J. Microstructure and mechanical properties of hypoeutectic Al-Si composite reinforced with TiCN nanoparticles. Mater. Des. 2016, 95, 545-554. [CrossRef]

12. Zhou, D.; Zeng, W.; Zhang, D. A feasible ultrafine grained Cu matrix composite microstructure for achieving high strength and high electrical conductivity. J. Alloys Compd. 2016, 682, 590-593. [CrossRef]

13. Ziemnicka-Sylwester, M. The Cu matrix cermets remarkably strengthened by TiB2 "in situ" synthesized via self-propagating high temperature synthesis. Mater. Des. 2014, 53, 758-765. [CrossRef]

14. Wang, F.; Li, Y.; Yamanaka, K.; Wakon, K.; Harata, K.; Chiba, A. Influence of two-step ball-milling condition on electrical and mechanical properties of TiC-dispersion-strengthened $\mathrm{Cu}$ alloys. Mater. Des. 2014, 64, 441-449. [CrossRef]

15. Wang, F.; Li, Y.; Wang, X.; Koizumi, Y.; Kenta, Y.; Chiba, A. In-situ fabrication and characterization of ultrafine structured $\mathrm{Cu}$-TiC composites with high strength and high conductivity by mechanical milling. J. Alloys Compd. 2016, 657, 122-132. [CrossRef]

16. Wensley, C.A. Processing and Properties of Amorphous NiW Reinforced Crystalline Ni Matrix Composites. Master's Thesis, Virginia Tech, Blacksburg, VA, USA, 2005.

17. Thakur, S.K.; Paramsothy, M.; Gupta, M. Improving tensile and compressive strengths of magnesium by blending it with aluminium. Mater. Sci. Technol. 2010, 26, 115-120. [CrossRef]

18. Carvalho, O.; Buciumeanu, M.; Soares, D.; Silva, F.S.; Miranda, G. Evaluation of CNT Dispersion Methodology Effect on Mechanical Properties of an AlSi Composite. J. Mater. Eng. Perf. 2015, 24, 2535-2545. [CrossRef]

19. Öksüz, K.E.; Şimşir, M.; Şahin, Y. Characterization of Diamond Impregnated B4C/Fe-Co MMC. In Proceedings of the Euro International Powder Metallurgy Congress and Exhibition, Euro PM 2011, Barcelona, Spain, 9-12 October 2011.

20. Karabulut, S.; Gökmen, U.; Çinici, H. Study on the mechanical and drilling properties of AA7039 composites reinforced with $\mathrm{Al}_{2} \mathrm{O}_{3} / \mathrm{B}_{4} \mathrm{C} / \mathrm{SiC}$ particles. Compos. Part B Eng. 2016, 93, 43-55. [CrossRef]

21. Tomolya, K.; Janovszky, D.; Sycheva, A.; Sveda, M.; Ferenczi, T.; Roosz, A. Peculiarities of ball-milling induced crystalline amorphous transformation in Cu-Zr-Al-Ni-Ti alloys. Intermetallics 2015, 65, 117-121. [CrossRef]

22. Qiu, W.T.; Pang, Y.; Xiao, Z.; Li, Z. Preparation of W-Cu alloy with high density and ultrafine grains by mechanical alloying and high pressure sintering. Int. J. Refract. Met. Hard Mater. 2016, 61, 91-97. [CrossRef]

23. Gácsi, Z.; Kovács, J.; Pieczonka, T. Characterisation of particle arrangement using the radial distribution function. In Proceedings of the 3rd International Powder Metallurgy Conference, Ankara, Turkey, 4-8 September 2002; pp. 542-551.

24. Wang, Z.; Georgarakis, K.; Nakayama, K.S.; Li, Y.; Tsarkov, A.A.; Xie, G.; Dudinał, D.; Louzguine-Luzgin, D.V.; Yavari, A.R. Microstructure and mechanical behavior of metallic glass fiber reinforced Al alloy matrix composites. Sci. Rep. 2016, 6, 24384. [CrossRef] [PubMed]

25. Kolednik, O.; Unterweger, K. The ductility of metal matrix composites-Relation to local deformation behavior and damage evolution. Eng. Fract. Mech. 2008, 75, 3663-3676. [CrossRef]

(c) 2017 by the authors. Licensee MDPI, Basel, Switzerland. This article is an open access article distributed under the terms and conditions of the Creative Commons Attribution (CC BY) license (http:/ / creativecommons.org/licenses/by/4.0/). 